\title{
¿CABALLO DE TROYA O CABEZA DE TURCO?: LAS EMPRESAS PÚBLICAS CHILENAS EN LA GUERRA FRÍA, CA. 1940-1990
}

\author{
Guillermo Guajardo Soto \\ Universidad Nacional Autónoma de México \\ guillermo.guajardo@unam.mx
}

\section{RESUMEN}

El artículo analiza la trayectoria de las empresas públicas chilenas entre las décadas de 1940 y 1990. Se sostiene que las empresas públicas no fueron un Caballo de Troya que contenían un proyecto estatista, ni fueron culpables de una conducta populista de la economía en el pasado. Pueden ser consideradas como instrumentos que utilizaron gobiernos de distinto signo político para llevar a cabo proyectos diversos. A través de la reconstrucción del rol que jugaron las empresas públicas durante el período de estudio, se muestra que ellas no tuvieron un carácter populista, progresista o de desarrollo por sí mismo. Más bien, representaron proyectos enfrentados, entre lo que fue el Estado Empresario, el Área Social de la Economía, la Empresa Integrada y otras categorías presentes hasta la década de 1970.

Palabras clave: Empresas públicas, Estado, Guerra Fría, Privatizaciones, Chile. 


\title{
TROJAN HORSE OR SCAPEGOAT? CHILEAN STATE \\ COMPANIES IN THE COLD WAR, CA. 1940-1990
}

\begin{abstract}
This paper analyzes the performance of Chilean state companies between the 1940s and the 1990s, arguing that they were neither the Trojan horse of a statist project nor to blame for the populist management of the economy seen in the past. They can be viewed as a tool used by governments of different political colors to implement diverse projects. By reconstructing the role played by state companies during the period in question, the paper shows that they were not in themselves of a populist, progressive or developmental nature but, rather, represented contrasting projects related to the state as producer, the social area of the economy, the integrated state and other categories seen through to the 1970s.
\end{abstract}

Keywords: State Companies, State, Cold War, Privatizations, Chile 


\section{INTRODUCCIÓN}

Chile, hasta las masivas privatizaciones de la dictadura cívico-militar (1973-1990), tuvo un aparato muy diverso de intervención estatal para la producción de bienes y servicios, que fue determinante en su conformación económica y social. Tras cuatro décadas, todavía se conserva un núcleo de empresas públicas en la exportación de cobre, distribución de bienes y provisión de servicios. Sin embargo, llama la atención que a pesar de la larga historia de esas empresas y de un proceso tan radical de privatización, sigue siendo escaso el interés por la investigación en este campo (Guajardo 2018, Barría 2015, Guajardo y Labrador 2015). Varias pueden ser las explicaciones. Quizás la más obvia es que la documentación pasó a manos privadas y que el poco interés es parte de la corrección política de la transición, de no explorar en la historia de los activos públicos que se vendieron bajo un marco dictatorial. Ello tuvo continuidad en democracia, conformándose grandes conglomerados empresariales a partir de antiguas empresas públicas, que ejercen una fuerte influencia sobre los poderes públicos, como ocurre con la ex Sociedad Química y Minera de Chile, hoy SQM (Monckeberg 2015, Gárate 2015a). Finalmente, a esto contribuye la nula política de preservación documental en este campo, a diferencia de otros países en los que se rescataron los materiales con interés patrimonial. En ese sentido, desarrollar una agenda de investigación histórica en este campo sería necesario, ya que en el Chile contemporáneo siguen predominando los mitos y leyendas negras sobre la intervención estatal en la economía, así como el olvido de recursos que hoy en día tienen un alto valor estratégico internacional, como el litio, o bien la importancia de servicios que siguen siendo críticos para la vida, como el agua y la electricidad, que durante décadas fueron desarrollados por el Estado.

Para conocer esa historia, en este artículo se presenta un panorama sobre el papel que cumplieron las empresas públicas en Chile durante el período de la Guerra Fría. Consideramos que estas organizaciones no tuvieron un carácter populista, progresista o de desarrollo por sí mismo, pero sí representaron proyectos enfrentados, entre lo que fue el Estado empresario, el área social de la economía, la empresa integrada y otras categorías presentes hasta la década de 1970, que más tarde sucumbieron. Chile durante la Guerra Fría, por factores tanto locales como externos, fue un laboratorio para aplicar o testear modelos internacionales, alcanzando un alto grado de radicalidad durante el gobierno socialista de Salvador Allende (1970-1973) y la dictadura cívico-militar (1973-1990). En el período de Allende las empresas públicas se emplearon como instrumentos expropiatorios, para después del golpe militar de 1973 ser "normalizadas" dentro de las definiciones ideológicas de la bipolaridad global, de las disposiciones de la Constitución de 1980 y de las ideas de los actores políticos y empresariales. Las empresas públicas 
chilenas no fueron un Caballo de Troya que contenían un proyecto socialista, ni fueron culpables de una conducta populista de la economía en el pasado. Más bien fueron instrumentos organizacionales para gobiernos de distinto signo político y para proyectos diversos. Esto fue muy claro durante la Guerra Fría (1948-1991), cuando dentro de un marco de polarización ideológica, las empresas públicas y los servicios públicos se crearon y expandieron con recursos y tecnología de los Estados Unidos, con créditos del Export-Import Bank of the United States (Eximbank), de la Alianza para el Progreso y del Banco Mundial. Hubo receptores estatales directos, como la Empresa de los Ferrocarriles del Estado (EFE), la Empresa Nacional de Electricidad S. A. (ENDESA) y entidades como la Corporación de Fomento de la Producción (CORFO), hasta llegar a fines de la década de 1960 a conformarse un tenso mix de capital público y privado.

Dentro de una polarización de planes e ideas, las empresas públicas fueron vistas por sectores empresariales como un instrumento cuestionador de la propiedad privada, en sintonía con la lucha dada al interior del Estado por dos versiones excluyentes de modernidad ofrecidas por el socialismo y el capitalismo liberal, con una tensión creciente entre planeación y desregulación de las fuerzas de mercado (Westad 2011: 10. Loth 2011: 503). Pero también hubo una línea divisoria, que requiere de más investigación, dada por el hecho de que no todo el capital y la tecnología estadounidense fueron parte del juego de la Guerra Fría. Desde el siglo XIX, los Estados Unidos de América iniciaron una fuerte competencia comercial con Europa, que se incrementó tras la Primera Guerra Mundial y después de la Depresión de 1929 se consolidó como prestamista de los gobiernos, junto con una fuerte ofensiva en América Latina con el Eximbank. La Segunda Guerra Mundial devino en ayuda para el desarrollo y en solidificar su presencia económica y desde la década de 1950 se marcaron los rasgos ideológicos de la ayuda estadounidense, presentes en las becas para postgrados o bien en los préstamos para una central eléctrica. Pero también había un mercado, casi libre, y muy dinámico de bienes y servicios estadounidenses que podían ser adquiridos sin pasar por el visado ideológico de la bipolaridad este-oeste. Frente a esa oferta, los gobiernos chilenos entre las décadas de 1940 y 1990 , recibieron ayudas como parte de las estrategias del anticomunismo y también compraron libremente tecnologías y asesorías, de la Alianza para el Progreso o para equipar la vía chilena al socialismo.

El texto está organizado para explorar esa historia. Se inicia indicando lo tenue de este campo de estudios a pesar del gran peso que tuvieron las empresas públicas, para luego ubicarlas dentro de la Guerra Fría, señalando que el llamado Estado empresario no acabó por las privatizaciones llevadas a cabo por el régimen cívico militar, sino un poco antes, con el experimento 
socialista que buscó abolir el capitalismo utilizando a las empresas públicas como instrumento expropiatorio de la propiedad privada. El golpe militar de 1973 abrió un período de diecisiete años durante el cual fueron vendidas y ajustadas a una lógica privada, aunque paradójicamente en ese mismo período se creó la única y mayor empresa pública de la historia chilena para explotar el cobre nacionalizado en 1971. En las conclusiones se planea el carácter instrumental como también el vacío de pensamiento económico del estatismo chileno, que fue más táctico que estratégico. El propósito final es entregar un marco general para la discusión y para una agenda de investigación impostergable.

\section{EXPLORANDO EN EL OLVIDO Y EN LOS MITOS SOBRE LA EMPRESA PÚBLICA EN CHILE}

Las bases de las empresas públicas se hunden en el período colonial, siendo ejemplo de ello la Casa de Moneda y en el siglo XIX los Ferrocarriles del Estado y otras actividades, aunque fue en la década de 1930, cuando por los efectos de la Depresión y del impacto del terremoto de Chillán de 1939, se impulsó la industrialización sustitutiva de importaciones (ISI), se crearon empresas estatales de servicios y se construyó una nueva infraestructura, lo que amplió el papel del Estado en la economía. Esto último no fue una conducta exclusivamente chilena, porque en el mundo occidental las empresas públicas en ese momento eran un instrumento válido de intervención económica. En Chile se reflejó en un incremento del tamaño del sector público, que en 1968 alcanzó un 54\% en la inversión fija total, superando a las economías más grandes de América Latina, como Argentina (47\% en 1969), Brasil (39\% en 1968) y México (35\% en 1967) (Banco Interamericano de Desarrollo et al. 1979: 25, cuadro 1). Para 1980, después de darse una drástica reducción de las empresas públicas, todavía la inversión fija de estas últimas como porcentaje de la inversión bruta era alta, con un 15,8\%, muy cercano a Argentina y México (Devlin 1993: 157, cuadro 1). Pero, a pesar de estas evidencias todavía sigue siendo muy escasa la masa de estudios sociales e históricos sobre estas empresas y persisten leyendas negras, que fueron y siguen siendo funcionales a un proceso privatizador carente de toda transparencia, persistiendo incluso en el mundo académico.

Un aspecto inicial para despejar lo anterior es que para mediados del siglo $\mathrm{XX}$ en el derecho administrativo chileno, las actividades empresariales del Estado eran consideradas servicios del Estado creados para satisfacer necesidades colectivas de utilidad pública (Infante 1961: 8-40); es decir, cuando se experimentaba su expansión no tenían una norma específica ni se calificaban con un carácter empresarial, ambigüedad que encontraba sus antecedentes en el siglo XIX, en lo que Véliz llamó "acuerdo de 
caballeros", acuerdos oligárquicos que delimitaron las áreas en las que el Estado invertiría y apoyaría a ciertos grupos de poder y en otras que serían para el capital privado. Por esto la legislación proteccionista chilena, desde sus orígenes, no tuvo el elemento de intervención estatal directa y mantuvo el privilegio, la subvención o la concesión, incluyendo privilegios cuasi monopolistas (Véliz 1961: 266). No obstante, las tempranas áreas de participación pública se reflejaron en las estadísticas económicas, realidad que logró detectar Humud (1974) en la estructura del gasto público; ya que desde mediados del XIX tomaron relevancia actividades como como los ferrocarriles y los caminos (Humud 1974: 11). Fue durante los decenios de 1960 y 1970 cuando empezaron a difundirse estudios que indicaban la gran relevancia histórica sobre la intervención estatal en la economía, sin embargo, la polarización política, la represión intelectual de la dictadura y la simultánea privatización, forjaron un relato funcional y una leyenda negra sobre las empresas públicas. Ejemplo de esto lo dio Mamalakis, al indicar que la temprana intervención del Estado chileno en sectores como el ferroviario, fue inadecuada para producir un mercado de transporte eficiente, debido a que el Estado asumió la producción de servicios de transporte antes que el sector privado y antes de que se generaran reglas óptimas en el mercado de transporte (Mamalakis 1989: 284). Por este motivo, el Estado chileno habría desarrollado una vocación "cleptocrática" para beneficiar a ciertos grupos sociales a través de la intervención en los mercados libres y en la producción de bienes semi-públicos y particulares (coincidiendo en este punto con la tesis de Véliz sobre el beneficio a ciertos grupos), como transporte ferroviario, agua, vivienda, hasta llegar a la hipertrofia y anarquía que estalló en $1973^{1}$. En ese misma línea, para Dittborn y Martínez (1984) las empresas públicas desde sus orígenes en el siglo XIX solo buscaron "lograr o afianzar un poder monopólico", por lo que empresas como la EFE y la Línea Aérea Nacional (LAN) influyeron negativamente en la legislación chilena, al ser favorecidas por sobre el sector privado y perjudicar a los sustitutos de los servicios que ellas prestaban "con el evidente propósito de lograr afianzar su poder monopólico"; lo más sorprendente de estos autores es que afirmaron que "No conocemos la intención que el legislador y el ejecutivo tuvieron al dictar esta legislación" (Dittborn y Martínez 1984: 138). Recientemente, y después de un notable trabajo de recopilación de estadísticas históricas, Díaz y Wagner (2016) señalaron que desconocían la historia del conjunto del sector público chileno: "Es posible, pero no lo sabemos con exactitud, que antes de 1887 el fisco haya realizado algún gasto en infraestructura cuyo registro sea parte de la contabilidad de otros ministerios existentes en la época" (Díaz y Wagner 2016: 43).

1 Entrevista concedida por Mamalakis en 1986 a la historiadora Lucía Santa Cruz. 
Este panorama de trabajos académicos muestra una falta de preocupación por el tema o bien la idea de que toda intervención estatal en el pasado fue, al parecer, guiada por fines corporativos y una "pulsión estatista" y populista, lo que explicaría la necesidad de reformas pro-mercado ${ }^{2}$. Sin embargo, si tomamos lo revisado desde Véliz (1961) a Díaz y Wagner (2016), la historia de las empresas públicas muestra que su actividad se inició durante la república oligárquica como parte de los "acuerdos de caballeros" y que luego continuó bajo un marco de ascenso de fuerzas populares y de clases medias, es decir también atendió la racionalidad económica de otros grupos sociales. Así, la empresa pública fue adquiriendo un carácter casuístico, no planeado y de coyuntura política, lo que matizaría la idea de que el aparato público se fue dotando de una gran capacidad técnica y racional, de alcance nacional y con orientación distributiva. Esto último lo planteó Fernando Musso (1985), desde la óptica de la Administración Pública, al destacar un defecto de origen: la definición del papel de las empresas públicas se dio dentro de la matriz ideológica de un Estado liberal-burgués, desde donde se desplegaron extensiones o modificaciones hacia un rol empresarial, benefactor o providencia (Musso 1985: 13), o bien, cumplir un rol expropiatorio. A una idea similar llegó, pero desde la Historia, Gabriel Salazar (2015) al señalar que la gestación del Estado empresario fue una intervención superpuesta a la Constitución de 1925, que las consideraba servicios. Por estas razones el estatismo empresarial chileno fue muy laxo en su formalización, no se concentró en un ministerio coordinador o gestor de las empresas estatales, como lo pudo ser el Ministerio de Fomento, creado a fines de 1927, o en la CORFO, corporación autónoma sin rango ministerial, creada en 1939 . Se privilegiaron las aportaciones de capital a compañías específicas o se crearon empresas como sociedades anónimas, coordinando los intereses sectoriales con las tareas financieras y empresariales, sin sustituir la actividad privada (Muñoz Gomá 1986: 78, 107). En esto tuvieron gran importancia los cambios que se dieron entre las décadas de 1920 y 1930.

\section{EL FIN DE LA REPÚBLICA OLIGÁRQUICA Y EL ASCENSO DEL ESTADO EMPRESARIO}

La Depresión de 1929 tuvo efectos drásticos para una economía como la chilena, basada en la exportación de materias primas y en una fuerte integración al comercio internacional, acompañado de un severo impacto

2 Esto último corresponde a una conceptualización forzada, de fines de la Guerra Fría, sobre el populismo económico y su macroeconomía que ignoró las definiciones sociológicas, politológicas y la historia sobre el populismo clásico, pero que fue impulsado por Dornbusch y Edwards (1990, 1991). 
socio-político, pero que no adquirió un carácter revolucionario, ya que las viejas estructuras no fueron derrumbadas, como la oligarquía terrateniente y minera, así como las instituciones militares y el latifundio, cuya persistencia feudal siguió hasta la década de 1960. Donde sí empezó a darse una fuerte transformación fue en el orden administrativo del Estado, al establecerse una plataforma de intervención en la economía que fue modificando y cuestionando el viejo orden, como también enfrentando los efectos de la Depresión. Para 1932 el impacto externo era severo, al reducirse en $78,3 \%$ las exportaciones y el producto en más de un tercio, demorando la recuperación hasta 1938, con un efecto productivo directo por la caída de las importaciones en un $83,5 \%$, dándose el paso a la sustitución de importaciones (Meller 1990: 65-67). No obstante, poco antes de la Depresión ya venían dándose cambios relevantes, marcados desde la elección en 1920 del presidente Arturo Alessandri Palma (19201925 y 1932-1938), quien asumió reformas postergadas, pero abrió un periodo de inestabilidad. En 1924 estalló una crisis política que derivó en una sucesión de intervenciones militares con un Comité Militar, una Junta Militar y una Junta de Gobierno que forzaron la aprobación de leyes sociales, renunció Alessandri y se promulgó una nueva constitución en 1925, que separó a la iglesia del Estado y le dio gran poder al ejecutivo. También se creó un nuevo tejido institucional, con el establecimiento en 1925 del Banco Central de Chile como única entidad emisora de circulante, del Servicio de Minas del Estado y, entre 1927 y 1928, de las cajas de Crédito Agrícola, Minero, Carbonero y el Instituto de Crédito Industrial. A fines de 1927, se estableció el Ministerio de Fomento, que elaboró los primeros planes económicos nacionales guiados por ingenieros civiles (Palma 1983: 165-192, Ibáńez 1983: 45-102).

Todo este nuevo tejido institucional le fue dando margen de maniobra a los gobiernos para enfrentar la Depresión de 1929, estimular la industrialización sustitutiva de importaciones y disponer de agencias públicas dedicadas al apoyo y la producción directa de bienes y servicios. De ese aparato surgió la CORFO en 1939 cuya función, en un primer momento, fue llevar adelante las tareas de reconstrucción tras el terremoto de Chillán de ese año, para luego crear empresas, representar la participación estatal en firmas privadas y coordinar los planes de inversión; fue una agencia semifiscal, de un carácter cuasigubernamental cuyo directorio estaba integrado por representantes del Estado y de empresarios, trabajadores e ingenieros (Silvert 1948: 13-14, 31-32). Al respecto, debe precisarse que la historia de las empresas públicas chilenas no se explica tan solo por la CORFO, por varias razones. La primera la señaló Silvert, en el sentido que ya había importantes entidades públicas, siendo ejemplos la EFE, la Empresa de Agua Potable de Santiago (1898), la Caja Hipotecaria (1855) y la LAN (1929), e incluso 
un primer núcleo piloto de "fomento", se incubó dentro de una empresa pública: en la década de 1920 se creó un Departamento de Fomento de EFE para incrementar la producción en las zonas aledańas a las vías férreas y de esa manera desarrollar tráfico (Guajardo 2007). Otro aspecto fue que las empresas estatales tuvieron muchos formatos organizacionales como empresas, sociedades anónimas, institutos, corporaciones y participaciones accionarias, algunas controladas por ministerios, municipalidades y filiales de otras empresas. Esto último fue posible porque, como lo señalamos más atrás, en la legislación chilena no había un estatus especial, hasta que en la Constitución de 1980 se normó su creación y campo de acción. Finalmente, cada empresa actuó en su mercado con márgenes de operación que, en gran parte, no se subordinaban a la CORFO, corporación de una jerarquía menor a las burocracias de los ministerios como los de Obras Públicas, Hacienda y Economía.

La lenta creación de agencias públicas, acompañada del desgaste del esquema de libre mercado, desde inicios del siglo XX se tradujo en el plano sociopolítico en una crisis del poder de la élite gobernante desde la creación de la República, que no había enfrentado revoluciones burguesas ni campesinas, teniendo gran eficacia para reprimir y contener las revueltas populares. Pero, desde 1920 debió compartir el poder con una burocracia en ascenso, con partidos políticos de base popular y con el intervencionismo estatal, lo que sería definitivo con el triunfo de una coalición de partidos de centro e izquierda, el Frente Popular, en la elección presidencial de 1938, perdiendo paulatinamente la capacidad para captar el producto del país. Según el estudio de Rodríguez Weber (2017), sobre el ingreso que captaba el 1\% de la población chilena entre 1913 y 1970, antes de la Primera Guerra Mundial el ingreso de ese segmento de población era superior a los Estados Unidos de América, Francia y Alemania y para 1938 la participación de la élite en el ingreso total era de un 28\%, que bajó en 1952 a 17\%, para recuperarse en la década de 1960 y llegar a un 16\% en el año de 1970, tras la reforma agraria. En ese marco el gobierno de Allende aceleró la redistribución del ingreso y cuestionó en forma frontal la propiedad privada, hasta que la dictadura detuvo la erosión del poder de la élite (Rodríguez Weber 2017: 59, $67,73)$. En ese período la pérdida de capacidad de captar ingreso, permitió el ascenso de nuevos grupos empresariales, como los industriales, y se crearon mecanismos de vinculación con las nuevas fuerzas políticas, aunque con el apoyo de las viejas élites, como fue el caso de la creación en 1934 de la Confederación de la Producción y del Comercio (CPC), por iniciativa de dos viejas entidades representativas de las élites empresariales, la Sociedad Nacional de Agricultura, fundada en 1838, y la Sociedad de Fomento Fabril, establecida en 1883. Esto hizo que la búsqueda de protección industrial fuera ambigua, según lo anotaron autores como Óscar Muñoz (1986: 80, 210- 
211) y Gabriel Salazar (2015: 449), ya que el capital privado vio a la actividad empresarial del Estado como una competencia desleal, prefiriendo que se crearan en nuevos sectores y que luego fueran vendidas al sector privado. Contradictoriamente la protección se acompañaba de "estatismo", que llevó al sector privado a participar en el aparato de representación empresarial ante los consejos de las empresas públicas, servicios y agencias fiscales, siendo parte de un complejo "corporativismo de Estado" cuyas "funciones estimuladoras" imponían otros costos, como tributación y aportes a la seguridad social. Todo ello fue convirtiendo al aparato público en la arena de pugnas de redistribución del ingreso, que escalaron en la medida en que la estructura social se complejizaba y se fortalecían los grupos de presión.

Estos cambios se acompañaron de un importante giro político de la derecha chilena entre las décadas de 1920 y 1930. En un primer momento adhirió a las ideas nacionalistas y antiliberales influidas por Spengler, que vinculaban la democratización con la decadencia y la "crisis moral" de la sociedad chilena desde principios del siglo XX, en un marco de declive oligárquico frente al avance de nuevos actores sociales populares y urbanos (Gazmuri 1980, Salazar 1983). Amplios sectores de las clases medias, la burocracia, los partidos políticos y las fuerzas armadas tuvieron fuertes simpatías por movimientos internacionales, como el nacionalsocialismo alemán y por figuras autoritarias locales, como el coronel Carlos Ibáńez quien asumió la presidencia como dictador (1927-1931). Ibánez llevó a cabo la modernización administrativa, dio el paso hacia una mayor diversificación exportadora, también impulsó la industrialización sustitutiva de importaciones, golpeando simultáneamente a la oligarquía y a los sectores más radicales del proletariado para abrir camino a las clases medias (Domínguez 1996: 47, 57). Después de 1945, y tras la derrota del fascismo, se dio un segundo giro con una corriente que desde 1934 venía elaborando una síntesis conservadora, que fusionó una visión elitista y antidemocrática en lo político y antiestatista en lo económico, expresado en la revista Estudios dirigida por el historiador Jaime Eyzaguirre. Con esto último, la derecha tomó una posición crítica con respecto al Estado, porque tanto el socialismo como el fascismo habían coincidido en la solución estatal a los problemas de producción, con una amplia movilización de masas (Cristi y Ruiz 1999: 84, 92). Esta crítica durante la Guerra Fría encontró un ambiente favorable, por la oposición a toda forma de intervención, adoptando un anticomunismo de amplio espectro. Ello permearía el discurso y el programa de los órganos empresariales, que pronto migraría a la academia, cuyo exponente sería el ingeniero Jorge Alessandri Rodríguez, presidente de la CPC y luego de la República (1958-1964). Alessandri fue abiertamente critico de las posturas que estaban en contra del libre mercado en un momento de auge del proteccionismo, incluso en criticó en 1955 las políticas de integración 
regional promovidas por entidades internacionales como la Comisión Económica para América Latina y el Caribe de Naciones Unidas (CEPAL), porque afectaban la capacidad de inversión y dañaban la relación con los Estados Unidos (Salazar 2015: 438), ubicándose así en uno los bandos de la Guerra Fría.

\section{UNA ESTACIÓN REMOTA EN LOS DEBATES INTERNACIONALES}

Para los chilenos la Guerra Fría quedó marcada a fuego por las consecuencias de una sucesión de políticas de reforma, revolución y autoritarismo que se será recordada por el perdurable ícono del dictador de lentes obscuros, el general Augusto Pinochet (Gárate Chateau 2015b: 87-114). Sin embargo, dentro de los grandes balances sobre este período histórico, la huella chilena es débil en obras como The Cambridge History of Cold War (2011), o en las de Powaski (2000) y de Winock (1994), que presentan escasas o nulas referencias a Chile, frente al mayor registro de Cuba y América Central ${ }^{3}$. Incluso en las extensas memorias del embajador soviético en Washington entre 1962 y 1986, Anatoly Dobrynin, no hay referencias sobre la ruta chilena al socialismo ni a la dictadura (Dobrynin 1998). Y es que por su lejanía, posición y recursos el país estaba lejos de los grandes juegos estratégicos, aunque tras la caída del Muro de Berlín se han ido develando evidencias estadounidenses y soviéticas sobre el activo involucramiento de distintos actores políticos e institucionales chilenos con las potencias, cuyas opciones se moldearon a ideologías de alcance global (Harmer y Riquelme Segovia 2014, Huneeus 2009, Fermandois 1998). Es decir, el país se ubicó en la Guerra Fría a pesar de no tener una importancia estratégica, ni experimentar una ocupación extranjera ni una guerra civil, sino porque las fuerzas políticas locales quisieron emular "en lo ideológico, al gran marco de la confrontación global” (Fermandois 1998: 152-153).

Y esa toma de posición empezó durante la Segunda Guerra Mundial, cuando el país trató de mantenerse neutral, hasta que en 1943 cedió ante los Estados Unidos de América y se inscribió en el bando aliado. Tras la victoria aliada sobre el Eje, se buscó marcar una autonomía en las ideas y políticas con la instalación en Santiago en 1948 de la sede de la CEPAL que, con sus propuestas histórico-estructuralistas y búsqueda de la integración latinoamericana, se opuso al consenso impulsado por los Estados Unidos de libre mercado y de crítica al dirigismo público. Pero la toma de posición en la bipolaridad naciente fue rápida, ya que

3 Las tres entradas más importantes son Chile, Allende y Pinochet sin constituir una sección, son referencias en algunas páginas. En la obra de Leffler y Westad (2011), de tres volúmenes y casi dos mil hojas, estas palabras se encuentran solo en quince. 
en ese mismo año se promulgó la llamada Ley Maldita, que proscribió al Partido Comunista. Esta norma fue derogada en 1958, aprobándose en su reemplazo una disposición más amplia de la Ley de Seguridad Interior del Estado, en la que se tipificaron los delitos al orden público y en caso de amenaza, se subordinaba la administración civil al mando militar (Ley 12.927); esa norma le dio eficacia al golpe militar de 1973.

Con esos contrapuntos, desde esos años y hasta la década de 1970, en Santiago se desarrolló un ambiente de debates entre sociólogos, politólogos, demógrafos y economistas latinoamericanos desde varios núcleos de análisis, como la CEPAL, el Centro Latinoamericano de Demografía, el Instituto Latinoamericano de Planificación Económica y Social, la Escuela Latinoamericana de Economía, la Facultad Latinoamericana de Ciencias Sociales entre otras (Brunner 1999: 72-77. Soares 2001: 129-130). Marco en el cual la Universidad de Chile participó como la principal instancia en la que coexistían diversas corrientes como la escuela histórica alemana, la revolución keynesiana, el estructuralismo, la planificación y la dependencia. En la década de 1950 se inició un programa de historia económica en su Instituto de Economía y a fines del decenio de 1960 se creó el Centro de Estudios Económico-Sociales, para desarrollar una teoría marxista de la dependencia (Kay 1989, Cárdenas 2015). Frente a estas posturas desde el decenio de 1950 se levantó una alternativa apoyada por sectores empresariales y académicos en contra de las propuestas planificadoras, distributivas y de integración regional, tal como lo comprobaron Palma y Marcel al estudiar la visita que hizo a Chile en 1956 el economista de Cambridge y reconocido postkeynesiano, Nicholas Kaldor, invitado a la CEPAL por Raúl Prebisch. Durante su estancia elaboró un ensayo que cuestionó la distribución del ingreso en Chile y la necesidad de aplicar impuestos a las rentas más altas, para incrementar la tasa de ahorro y detener la alta propensión al consumo de su clase empresarial. A pesar del aparente progresismo santiaguino, su estudio no pudo ser publicado al ser atacado por la derecha que llevó a Alessandri a la presidencia (Palma y Marcel 1990: 87-90).

Corolario académico de esta confrontación fue la firma en 1956 del convenio entre la Pontificia Universidad Católica de Chile (PUC) y la Universidad de Chicago, apoyado por la International Cooperation Administration (más tarde conocida como USAID) para establecer un nuevo currículo de licenciatura economía y enviar estudiantes chilenos a Chicago (Valdés 1995:126). La Universidad Católica adoptó esa escuela por ser "conservadora desde el punto de vista de su ortodoxia clásica", formando a generaciones de economistas chilenos, quienes se consideraron con mejores credenciales académicas que las que provenían del marxismo, del keynesianismo y de las soluciones generadas por la CEPAL, la Universidad 
de Chile y otros centros, ya que fueron alumnos de destacados economistas y de Premios Nobel de la ortodoxia neoclásica, como Theodore Schultz, Milton Friedman, George Stigler, Gary Becker, Paul Samuelson y Kenneth Arrow (Baraona 1994: 49-51). Sus ideas convergían con la crítica liberal que había lanzado Friedrich A. Hayek, en Camino de servidumbre (1944), que homologaba la tiranía con las políticas socialistas y la planificación económica llevada a cabo en la Unión Soviética y en Occidente (Hayek 2000: 33). Aunque sólo "convergían", ya que de acuerdo al estudio de Caldwell y Montes (2015), en esa época dichos postulados libertarios eran poco conocidos en Chile y tuvieron más difusión cuando el mismo Hayek visitó el país en 1977 y 1981 . Más bien lo que se dio durante las décadas de 1950 y 1960 fue la forja de la visión abstracta y extremadamente teórica de los economistas monetaristas chilenos, dada dentro de lo que Deane llamó la "contrarrevolución monetaria", la cual arrancó desde la Universidad de Chicago, sede de una vigorosa tradición de individualismo liberal que justificó las soluciones de mercado a los problemas de política económica (Deane 1993: 194, 197, 200).

El año de 1958 fue determinante en el enfrentamiento político entre posturas ortodoxas y heterodoxas, que se hicieron presentes en la elección presidencial que enfrentó a las opciones políticas que fueron las más importantes hasta 1970, y en las que ganó Jorge Alessandri Rodríguez como representante de la derecha, quien derrotó por un escaso margen al candidato socialista Salvador Allende, del Frente de Acción Popular. En tercer lugar, quedó el candidato democratacristiano Eduardo Frei Montalva. El programa de Alessandri contenía un diagnóstico sobre problemas transversales presentes en los programas de los otros candidatos, como el estancamiento económico, la baja producción agrícola y el crecimiento de la burocracia; pero sus soluciones eran distintas y apuntaban a establecer la libre competencia liderada por los empresarios y la actividad privada, disminuir la protección aduanera para tener libertad de importación, modernizar la industria local, bajar costos y aumentar productividad (Alessandri 1958: 13, 14). Tampoco consideró la integración regional, ya que para Alessandri había una insuficiencia de medios de transporte y la capacidad de consumo de la región Latinoamericana era baja, siendo mejor impulsar mercados seguros y recíprocos (Alessandri 1958: 24-26). Es decir, el presidente en ese momento se ajustó a la postura de los Estados Unidos de América que era impulsada por el Departamento de Estado a través del Secretario Adjunto de Estado para América Latina, Thomas Mann, quien abiertamente desacreditaba las propuestas de la CEPAL. Testigo de ello fue el destacado economista mexicano Víctor L. Urquidi, quien, como funcionario gubernamental, recibió en 1959 la visita de funcionarios de Mann quienes promovían "olvidarse de la CEPAL y sus mecanismos de 
integración” (Urquidi 1998: 265).

\section{EL ESTADO EMPRESARIO ENTRE EL DESARROLLO Y W.W. ROSTOW}

La década de 1960 fue fundamental para las empresas públicas por el programa de reformas que asumieron los gobiernos chilenos, por la reconstrucción después de un terremoto que devastó el sur del país y por las iniciativas estadounidenses para la América Latina. La gestión gubernamental quedó bajo una gran presión para resolver las exigencias de los organismos financieros internacionales que otorgaban créditos, como el Banco Interamericano de Desarrollo (BID), el Banco Mundial y el Eximbank, que aportaban recursos a la CORFO (Nazer 2009: 115). Desde esos ańos una fuente muy importante de recursos fue la Alianza para el Progreso (APP), impulsada desde 1961 por el presidente John F. Kennedy, que exigió a los gobiernos latinoamericanos establecer planes nacionales de desarrollo con objetivos claros de inversión interna, estabilidad monetaria y un equilibrio externo de pagos. Esos recursos no estaban destinados a cumplir fines técnicos para el desarrollo, sino impedir el avance de partidos marxistas en la región después de dos señales adversas. La primera, fue la visita del vicepresidente Richard Nixon a Venezuela en 1958, en la cual constató un fuerte sentimiento antiamericano. La segunda fue el triunfo de la Revolución cubana en 1959, que en lo inmediato se tradujo en el apoyo estadounidense para crear el BID y en promover un fondo de ayuda social para la región (McPherson 2003).

Entre 1953 y 1961, los Estados Unidos gastaron en ayudas y préstamos US\$ 50.886.000.000 a nivel mundial. América Latina recibió sólo el $8,5 \%$, ya que el foco de atención estratégica estaba en Europa y Asia. Pero, desde 1958 Chile fue visto con preocupación tras la elección presidencial de ese año, cuando la Embajada estadounidense en Santiago advirtió que el senador socialista Salvador Allende si bien perdió, había logrado una gran cobertura nacional, fijándose como prioridad derrotarlo en la elección de 1964. A esa llamada de atención se agregó un evento catastrófico, los terremotos del 21 y 22 de mayo de 1960, que afectaron de Talca a Chiloé con un impacto económico severo, con un daño que fue estimado entre US\$ 350.000.000 a US\$ 400.000.000 por la Embajada de los Estados Unidos, en tanto que el gobierno chileno llegó a una cifra de US\$ 550.000.000, equivalente a dos tercios del presupuesto anual (Taffet 2001: 10, 77-78, 84-85, 87, 90). Con la reconstrucción el gobierno de Alessandri logró llamar la atención de la APP, pero también por los problemas agrarios y el avance de la izquierda. Por ello, en agosto de 1962, una special task force del gobierno de Kennedy decidió apoyar al Partido Demócrata Cristiano 
(PDC), transfiriéndose US\$ 160.000 en apoyos, ya que consideraron que la elección de 1964 sería símbolo de competencia entre este y occidente. Con el triunfo del candidato del PDC, Eduardo Frei Montalva (19641970) el gobierno de Lindon B. Johnson apoyó la reestructura de la deuda y promovió conversaciones entre las corporaciones del cobre con el gobierno para aumentar el control chileno sobre las minas (Taffet 2001: 123, 151-152).

La ayuda directa de los Estados Unidos para Chile entre 1959 y 1962, sumada a la de Europa y de agencias internacionales hizo la diferencia entre ingresos y gastos públicos, que totalizaron US\$720.000.000, de los cuales US\$ 372.500 .000 fueron directamente al gobierno chileno, en tanto que el resto fue para agencias gubernamentales, empresas públicas y el Banco Central. Por los daños del terremoto de 1960 se recibieron US\$ 110.000.000, en tanto que para proyectos específicos se entregaron US\$115.700.000 a fin de iniciar importantes obras de infraestructura, como los aeropuertos de Pudahuel en Santiago y de Concepción, la central hidroeléctrica de Rapel, un proyecto de ENDESA, el proyecto del río Maule, la construcción de autopistas, agua potable para Concepción y otras obras públicas. El Eximbank otorgó un préstamo directo a EFE por US\$ 20.000.000 y la CORFO recibió uno del Banco Mundial por US\$ 18.300.000 (Taffet 2001: 167-169), permitiendo que el Estado chileno avanzara sobre sectores tradicionalmente en manos privadas.

En particular, el gobierno del PDC recibió una fuerte ayuda estadounidense para llevar a cabo reformas de gran envergadura las cuales, paradójicamente, terminaron cuestionando tanto a la propiedad privada como a las corporaciones americanas. Desde 1965, el gobierno de Frei acercó posiciones con los partidos de izquierda para llevar a cabo la Reforma Agraria y la "chilenización" del cobre, mediante la compra de acciones de las grandes compañías cupríferas estadounidenses. A su vez, se incrementaron y refinaron las capacidades de intervención con la creación en 1967 de la Oficina de Planificación Nacional (ODEPLAN) para diseñar una estrategia integrada de desarrollo industrial. Para controlar los pagos por tecnología transferida, el uso y explotación de patentes y marcas se estableció la Comisión de Royalties del Banco Central de Chile y en 1969 se creó el Instituto de Investigación en Cobre y Metalurgia (Ossa 1972, Musso 1985, Palma 2012). Sin embargo, para 1970 el 1\% más rico de la población todavía concentraba un importante 16\% del ingreso nacional (Rodríguez Weber 2017), lo que se agravaba por el bajo crecimiento del producto por habitante, que entre 1967 y 1970 sumó un 0,6\% (Meller 1990: 105). Frente a esa realidad, el Estado chileno estaba presente en una diversidad de actividades económicas y para 1969 poco más de un 
tercio del capital de las sociedades anónimas era estatal (Superintendencia de Compañías de Seguros, Sociedades Anónimas y Bolsas de Comercio 1970: 10. También citado por Palma 2012). Pero este "corporativismo de Estado" chileno no era una excepción, era parte de un consenso internacional a favor de las empresas públicas, expresado en esa época por el economista estadounidense, Walt Whitman Rostow, conocido por su libro Las etapas del crecimiento económico (1960), quien había apoyado la creación de la Alianza para el Progreso, era un ferviente anticomunista, promotor del capitalismo y llegó a ser Consejero de Seguridad Nacional durante la guerra de Vietnam. Rostow, indicó en 1973 que los límites entre lo público y lo privado se definían de acuerdo con los problemas que debían enfrentarse, señalando que históricamente ninguna nación desarrollada había pasado por fases de puro laissez-faire, considerando que las relaciones entre la autoridad pública y la empresa privada hasta ese entonces eran de compañerismo y complementariedad (Rostow 1973). Sin embargo, Chile ya manifestaba signos de agotamiento de esa relación, porque el Estado empresario empezaba a asfixiar la capacidad acumulativa del sector privado en su conjunto y las relaciones eran más bien de recelo y de desconfianza (Salazar 2015: 421). A esto se sumaba la formación de una generación de economistas de la PUC dentro de la escuela neoliberal de Chicago, que era considerada una élite periférica y fanática opuesta tanto al keynesianismo, como a las pragmáticas relaciones entre mercado y Estado. El experimento socialista le dio la oportunidad de ser opción.

\section{EL PLANES EXTREMOS PARA ACABAR CON LA EMPRESA Y EL ESTADO EMPRESARIO}

A diferencia de la corriente de opinión que considera que el Estado empresario y el corporativismo estatal fue aliado de socialismo, la realidad es que no era del agrado ni de las corrientes marxistas, ni del nacionalismo de derecha. Durante el gobierno socialista de Salvador Allende, se alcanzó el más alto número de empresas públicas en la historia chilena, con 596 empresas, pero también llegó a su fin, ideológica y programáticamente, el modelo que se había estructurado desde la década de 1930, basado en una coalición de intereses entre el Estado, los empresarios y los sindicatos (Silva 1996: 40). Allende se apartó de esa ruta, ya que estableció tres áreas de propiedad: social, mixta y privada, en donde la propiedad social estatizaría a las empresas privadas para sustituir la "estructura predominante capitalista” (Palma 2012: 276), empleando mecanismos diversos como adquisiciones, expropiaciones y "tomas". Dentro de esa confrontación, el proceso expropiatorio de Allende debe separarse de la Reforma Agraria y de la nacionalización del cobre, que contaron con un amplio consenso político previo para enfrentar el poder terrateniente en el campo y a las 
corporaciones estadunidenses de la Gran Minería del Cobre. Para esto último en la Ley 17.450 del 16 de julio de 1971, que nacionalizó el cobre, se emplearon diversas disposiciones que ya estaban en la Constitución de 1925 (Bertelsen 1987:117-118).

Acabar con el Estado empresario quedó claro desde el primer informe del gobierno socialista, el 21 de mayo de 1971, cuando Allende señaló que su gobierno no mantendría el orden económico existente, porque seguiría los ejemplos de la Rusia soviética y de la China comunista, "naciones [que] con gran masa de población pueden, en períodos relativamente breves, romper con el atraso y ponerse a la altura de la civilización de nuestro tiempo", para hacer de Chile "la primera nación de la tierra llamada a conformar el segundo modelo de transición a la sociedad socialista" (Allende 1971: V-VI). En el laboratorio gubernamental se edificaría "una nueva estructura socioeconómica capaz de proveer a la propiedad colectiva", con el fin de poner en práctica un modelo nuevo de Estado, de economía y sociedad que harían realidad la vía chilena al socialismo (Allende 1971: VII, IX). El área de propiedad social de la economía sería "un todo único, integrado, capaz de generar todas sus potencialidades en corto y mediano plazo", que estaría acompañado de un sistema de planificación que reemplazaría al mercado (Allende 1971: XX). Y no habría soluciones intermedias:

Algunos pensarán que hay otros caminos. Pero formar empresas de trabajadores integradas al mercado liberal significaría disfrazar a los asalariados de supuestos capitalistas e insistir en un medio históricamente fracasado (Allende 1971: XXI).

Para superar esa condición, el gobierno socialista impulsó una amplia estatización utilizando un decreto ley de 1932, dictado durante la República Socialista, que autorizaba al Presidente de la República para declarar de utilidad pública empresas y establecimientos que producían y distribuían artículos de primera necesidad. Con este decreto y otros instrumentos, para 1972 el Estado controlaba todos los bancos privados medianos y pequeños ${ }^{4}$, y en la producción industrial la participación estatal pasó en 1970 del 3\% al 30\% en 1973 (Meller 1990: 73, Allende 1973: XII).

En un nivel operativo, los funcionarios que tomaron a su cargo ODEPLAN y CORFO se plantearon acabar rápidamente con lo que llamaron "capitalismo monopolista de Estado", esbozado en el llamado "Plan 71" expuesto en los primeros meses de 1971 en varias asesorías a funcionarios de empresas públicas y entidades estatales. El Plan buscó

4 El mecanismo aparece indicado en Martner (1988). 
acelerar el control de la economía no como una tarea técnica, sino política para acabar con el Estado empresario, que se consideraba como un instrumento de la expansión de la burguesía nacional en determinadas fases del desarrollo histórico, como había sido la creación de la misma CORFO. En 1970 el presupuesto fiscal era equivalente a un tercio del producto, pero su aporte era bajo siendo del orden del 14\% del producto, aunque se ubicaba en ramas decisivas de la economía como energía, transportes, banca, seguros y servicios de educación y salud que, en su conjunto, aportaban recursos al empresariado con subsidios, créditos y costos de preinversiones (ODEPLAN 1971: capítulo II, 21). Esto expresaba "la relación cada vez más estrecha entre los grandes monopolios y el aparato del Estado, vale decir, la centralización y unificación creciente del poder económico y el poder político" de la burguesía. La toma del poder en la rama ejecutiva del gobierno permitiría tener acceso al control "de todo este complejo aparato técnico de regulación, intervención y participación directa sobre la economía”, que sería el instrumento para una de las transformaciones fundamentales en las empresas públicas, dada por la participación de los trabajadores en la gestión y administración de las mismas (ODEPLAN 1971: capítulo VII, 6, 10, 14).

No puede olvidarse que, en ese mismo ańo, pero desde el otro extremo ideológico el llamado Frente Nacionalista Patria y Libertad, agrupación de extrema derecha nacionalista formada en 1970 y disuelta en 1973 una vez consumado el golpe de Estado, y que llevó a cabo atentados, sabotajes y estuvo detrás del intento de golpe militar del 29 de junio de 1973 en contra de Allende, también planteó acabar con la empresa capitalista y el Estado empresario. Para su dirigente, el abogado Pablo Rodríguez Grez, la empresa capitalista en ese entonces sufría una crisis definitiva e insuperable porque, "Su fundamentación económica y social no resiste la evolución de nuestro tiempo y su injusta estructura hace urgente substituirla", debido a que "es programada, dirigida y realizada por el capitalista en su provecho exclusivo". Al frente de lo privado, estaba el "Estado paternalista" para paliar la desocupación disfrazada con cargos y funciones inútiles (Rodríguez Grez 1971: 20). Para Patria y Libertad el gobierno de Allende buscaba reemplazar la empresa capitalista por la Empresa del Estado, transformando a todos en proletarios y al Estado en "empleador de todos los chilenos"; la propuesta nacionalista era de transformarla en la llamada "empresa integrada" de trabajadores, en la que estarían presentes todos los factores productivos como capital, trabajo y organización con el fin de participar balanceadamente en los beneficios de la creación de la riqueza (Rodríguez Grez 1971: 21). Propugnaban que el Estado promulgara un estatuto para la empresa a fin de regular el funcionamiento de la cogestión productiva. Además, el Estado solo podría autorizar la creación 
de empresas en que se estableciera la participación de trabajadores y del capital, lo que no excluiría a las empresas públicas, encargadas de asegurar la mantención del marco indispensable a todo proceso productor, como energía y combustibles, materias primas básicas, control de importaciones y otros (Rodríguez Grez 1971: 22-23).

En ese sentido, se había pasado de lo académico a un enfrentamiento abierto en la calle, siendo cuestionada la empresa como organización de factores, un obstáculo para reemplazar al mercado como asignador de bienes y servicios, por lo que se planteaban formas de planificación central o bien de cogestión. Como lo expuso José Cademártori, ministro de economía de Allende, el objetivo era la eliminación del mercado y se llevaría a cabo siguiendo "leyes objetivas comunes a todas las revoluciones contemporáneas". No hacerlo equivalía a "renunciar a la dirección de la sociedad", por lo que la ciencia reemplazaría al voluntarismo (Cademártori 1972-1973: 106). Para reemplazar el mercado, la CORFO apoyó el desarrollo de un sistema cibernético que combinaba un software con una red de comunicaciones para colectar datos económicos en tiempo real a través del país, transmitirlos al gobierno y conducir así el tránsito de la economía chilena al socialismo. Tal fue el llamado proyecto Synco (sistema de información y control) que, como señala Eden Medina (2011), hizo de Chile un experimento notable en plena Guerra Fría, al diferenciarse del totalitarismo soviético y cubano, porque ofrecía un balance entre control centralizado y descentralizado para prevenir, tanto la tiranía del autoritarismo como el caos de la libertad total. Lo paradójico es que se contrató a la firma Arthur Andersen para el software, se compraron los equipos a IBM y se contrató la asesoría de Stafford Beer, destacado consultor británico en cibernética e investigación de operaciones de la época (Medina 2011). Pero, el proyecto Synco llegó a su fin el 11 de septiembre de 1973, con el golpe de Estado que derrocó a Allende y canceló la noción de control estatal en la economía chilena.

\section{LA IMPLANTACIÓN AUTORITARIA DE LA NORMALIDAD EMPRESARIAL}

El golpe militar del 11 de septiembre de 1973 vino a implantar lo que Manuel Gárate (2012) llamó "una revolución capitalista", basada en el modelo económico neoliberal, guiado por una mínima participación del Estado en la actividad empresarial, dentro de un marco autoritario de restricción de las libertades y atomización del poder de negociación laboral. Se dio cuando todas las propuestas civiles habían alcanzado un alto grado de radicalidad, tanto de la izquierda, centro como derecha, que buscaban desechar el país existente. Los militares optaron por el modelo 
neoliberal, del cual no había experiencias en otros países pero que tras su aplicación durante diecisiete años alcanzó resultados irreversibles. Cambió el balance de poder al interior de la clase empresarial, al acabar con la industrialización sustitutiva de importaciones y favorecer a los grandes grupos económicos no orientados al mercado interno, conformándose desde 1975 una coalición de fuerzas empresariales y políticas que apoyaron la concentración del poder en el general Augusto Pinochet, que se acompañó de la desregulación del sector financiero y de una rápida privatización (Gárate 2012, Silva 1996: 80, 90, 98).

Las autoridades civiles y militares capturaron gran parte del producto del país a través de más de 500 empresas que cubrían servicios, manufacturas, banca, así como tierra reformada, minas de cobre nacionalizadas y obligaciones financieras internacionales. Lo primero que llevaron a cabo fue la devolución gratuita de 325 firmas bajo el control del Estado, que todavía no se habían transferido al sector público y que se entregaron a sus antiguos propietarios, pero bajo la condición de no entablar una acción judicial contra el gobierno (Stallings 2001: 35. Hachette 2000: 117). Otra acción se dio el 26 de octubre de 1973, cuando se declaró la reorganización toda la administración pública, incluyendo a las empresas públicas, pudiendo crear y suprimir organismos y empleos mediante decretos-leyes. No obstante, se mantuvo un amplio número de empresas bajo el control del Estado e incluso en 1976 se creó la Corporación Nacional del Cobre de Chile (CODELCO), una de las mayores empresas públicas chilenas, para asumir la administración de la gran minería del cobre nacionalizada en 1971. En el artículo 8 del decreto-ley de la entonces Junta Militar de Gobierno una de las consideraciones para su creación, fue que

[...] es conveniente consagrar un régimen legal que permita administrar las empresas nacionalizadas con flexibilidad y autonomía, indispensables para lograr los niveles de eficiencia requeridos para competir internacionalmente en el mercado del cobre y sus subproductos: que habilite al Gobierno para contar en todo momento con una apreciación global y completa del estado de los negocios de dichas empresas (Decreto Ley 1.350).

Los militares se aseguraron el control estatal de los ingresos para sus gastos en un momento de crisis económica, cuya base era la Ley del Cobre de 1958, que a fines de 1973 se reformó, aplicando el impuesto sobre ventas al exterior y fijando un piso mínimo de US\$ 90.000.000. Más tarde se le introdujo una reajustabilidad según el índice de precios al por mayor de los Estados Unidos (Varas y Fuentes 1994: 95). 
Lo anterior no detuvo la ola de privatizaciones, proceso a través del cual muchas empresas fueron adquiridas con créditos subsidiados por instituciones gubernamentales, utilizando como garantía los propios activos, lo que aumentó considerablemente la concentración de la propiedad. Durante la crisis económica de 1981 y 1982, las autoridades económicas echaron mano de las grandes empresas estatales para negociar su venta a cambio de mejores condiciones para el pago de la deuda externa, sirviendo de garantía e incluso como medio de pago ante los acreedores internacionales (Stallings 2001:36). Para mediados de la década de 1980 el sector público general, más los organismos descentralizados incluyendo a las empresas públicas, todavía era muy alto dentro del producto. Si bien era inferior a 1973, seguía siendo superior a 1965, dominando en sectores como la minería, industria, gas, agua y telecomunicaciones. Así, para 1987 CODELCO y otras dos empresas estatales cubrían cerca de la mitad de las necesidades de divisas del país; el Banco del Estado era clave para el crédito agrícola, en tanto que la CORFO y sus servicios lo eran en los créditos a pequeños y medianos empresarios (Larroulet 1987: 157, 159, 160).

Ejemplo relevante de lo anterior fue la política de compras nacionales que se implementó para enfrentar los graves efectos de la crisis económica desatada en 1982. El gobierno, a través del Ministerio de Economía, Fomento y Reconstrucción canalizó el poder de compra de las empresas y organismos estatales hacia productos y servicios de origen nacional. La comisión de bienes de capital de CORFO fue la encargada de implementar dicha política, para lo cual desde 1985 facilitó el acceso al sector empresarial de la información sobre las compras de 33 empresas públicas y organismos estatales, con el fin de que ese gasto fuera para "promover el desarrollo de nuevos productores nacionales y lograr una sustitución eficiente de importaciones" (CORFO 1987: III, 1).

Durante la ronda de privatizaciones entre 1984 y 1989 se vendieron empresas que tradicionalmente habían sido del Estado; se privatizaron total o parcialmente 27 empresas de teléfonos, telecomunicaciones, energía, acero, transporte aéreo y minería. Las únicas empresas que permanecieron al margen fueron CODELCO, ENAP, el Banco del Estado y EFE (Stallings 2001: 36-37). Las privatizaciones impulsadas tras la derrota del régimen militar en el plebiscito de 1988 no fueron para reducir el déficit público -en ese momento había superávit- sino quitarle margen de maniobra a las nuevas autoridades civiles. Ello ya había quedado asentado en la Constitución de 1980, texto que estableció que el Estado para desarrollar actividades empresariales o participar en ellas lo haría mediante una ley de quórum calificado, cumpliendo con la legislación común para las empresas privadas (Bertelsen 1987: 115, 119, 121-122). Además, se dejó un bloqueo 
en la Ley 18.971 publicada el 10 de marzo de 1990, un día antes de asumir el gobierno democrático, que estableció que cualquier persona puede denunciar las infracciones al artículo 19, número 21, de la Constitución si se siente perjudicado por la actividad de una nueva empresa pública (Ley 18.971).

\section{CONCLUSIONES}

¿Caballo de Troya o cabeza de turco? Durante el período de la Guerra Fría, Chile se ajustó en gran parte al patrón internacional de modelos económico-sociales en competencia, teniendo el antecedente de ser un país muy dúctil para adoptar ideas y modelos internacionales. Transversalmente, todas las fuerzas en el gobierno emplearon a las empresas públicas para mover factores, variando en número, tareas y orientaciones, frente a una administración central más estable. Hasta 1969 fue creciendo en Estado empresario concertado y con ramificaciones en sociedades anónimas, que no cuestionaba la propiedad privada, lo cual se modificaría con los experimentos más radicales que se sucedieron en los veinte ańos siguientes, ya en plena sintonía con la polarización ideológica internacional de modelos económico-sociales enfrentados. En ese sentido, desde 1973 los militares cambiaron la ruta, pero no el objetivo fijado por el gobierno socialista de llevar a cabo una transformación radical del país a través de una masiva reasignación de factores económicos, siendo las empresas públicas el mecanismo privilegiado para restablecer la normalidad capitalista.

Las fuerzas armadas chilenas adhirieron al anticomunismo, pero no devolvieron a las compañías estadounidenses -que habían colaborado con el golpe- ni las minas de cobre ni los teléfonos. Vendieron gran parte de los bancos e industrias confiscadas, pero la nacionalización del cobre de 1971 no fue revertida; no quisieron, como en Brasil y Argentina, establecer una industria nacional, ni buscaron, como en el Perú y Ecuador, llevar a cabo una redistribución de la riqueza con los recursos naturales nacionalizados. En cambio, montaron una nueva empresa pública de carácter rentista, CODELCO, de una magnitud histórica como lo había sido EFE y ENDESA, para sostener desde 1976 lo que sería un Estado empresario cuprífero, cuya actividad está acotada a las reglas de mercado. Llama la atención que a lo largo del período estudiado, CORFO fue la agencia pública presente en todos los modelos económicos chilenos después de 1940, conservando su autonomía corporativa para crear, vender, incubar y gestionar empresas públicas. Vacía de un pensamiento económico propio, pudo recibir créditos de la APP siguiendo los intereses estratégicos estadounidenses, se encargó de acabar con el capitalismo monopolista, para de ahí gestionar la venta de empresas públicas y activos públicos y 
estimular al sector privado con compras fiscales, todo gracias a una alta capacidad profesional, flexibilidad institucional y vacío programático. 


\section{REFERENCIAS}

Alessandri, J. (1958). Discurso-Programa del Candidato Independiente Don Jorge Alessandri. Santiago: Editorial Lord Cochrane.

Allende, S. (1971). Primer Informe de Gobierno ante el Congreso Pleno. Santiago: Talleres Gráficos del Servicio de Prisiones.

.(1973). Tercer Informe de Gobierno ante el Congreso Pleno. Santiago: Talleres Gráficos del Servicio de Prisiones.

Banco Interamericano de Desarrollo, Escuela Interamericana de Administración Pública y Fundación Getulio Vargas. (1979). Las Empresas Públicas en América del Sur y México. México: Limusa.

Baraona, P. (1994). Desarrollo y Estabilidad: Una Interpretación Histórica. Estudios Públicos, 53, 37-53.

Barría, D. (2015). El Rol de las Empresas del Estado en el Chile Posdictadura. En Guajardo, G. y Labrador, A. (Coords.), La Empresa Pública en México y en América Latina. Entre el mercado y el Estado. México: UNAM-CEIICH / Instituto Nacional de Administración Pública, A.C.

Bertelsen, R. (1987). El Estado Empresario en la Constitución de 1980. Revista Chilena de Derecho, 14, 115-125.

Brunner, J. J. (1999). Los Orígenes de la Sociología Profesional en Chile. En Devés, E., Pinedo, J. y Sagredo, R. (Eds.), El Pensamiento Chileno en el Siglo XX. México: Fondo de Cultura Económica, Ministerio Secretaría General de Gobierno (Chile), Instituto Panamericano de Geografía e Historia.

Cademártori, J. (1972-1973). Perspectivas y Tareas Revolucionarias en el Frente Económico. Revista de la Universidad Técnica del Estado, 11-12, 101-117.

Caldwell, B. y Montes, L. (2015), Friedrich Hayek and His Visits to Chile. The Review of Austrian Economics, 28 (3), 261-309.

Cárdenas, J. (2015). Una Historia Sepultada: El Centro de Estudios Socioeconómicos de la Universidad de Chile, 1965-1973 (a 50 Años de su Fundación). De Raíz Diversa, 2 (3), 121-140. 
Corporación de Fomento de la Producción (CORFO). (1987). Guía de Compras de los Organismos y Empresas del Estado. Año 1987. Santiago: CORFO.

Cristi, R. y Ruiz, C. (1999). Pensamiento Conservador en Chile (19031974). En Devés, E., Pinedo, J. y Sagredo, R. (Eds.), El Pensamiento Chileno en el Siglo XX. México: Fondo de Cultura Económica, Ministerio Secretaría General de Gobierno (Chile), Instituto Panamericano de Geografía e Historia.

Deane, P. (1993). El Estado y El Sistema Económico. Barcelona: Editorial Crítica.

Devlin, R. (1993). Las Privatizaciones y el Bienestar Social. Revista de la Cepal, 49, 155-181.

Díaz, J. y Wagner, G. (2016). Inversión y Capital: Chile, 1833-2010. Santiago: Instituto de Economía, Pontificia Universidad Católica de Chile.

Dittborn, J. y Martínez, G. (1984). Empresas Públicas: ¿Han Influenciado la Legislación? Estudios Públicos, 16, 137-146.

Dobrynin, A. (1998). En Confianza. El Embajador de Moscú ante Los Presidentes Norteamericanos de la Guerra Fría (1962-1986). México: Fondo de Cultura Económica.

Domínguez, F. (1996). Carlos Ibáñez del Campo: Failed Dictator and Unwitting Architect of Political Democracy in Chile, 1927-31. En Fowler, W. (Ed.), Authoritarianism in Latin America since Independence. Westport: Greenwood Press.

Dornbusch, R. y Edwards, S. (1990). Macroeconomics Populism. Journal of Development Economics, 32, 247-277.

. (Eds.) (1991). The Macroeconomics of Populism in Latin America. Chicago: University of Chicago Press.

Fermandois, J. (1998). ¿Peón o Actor? Chile en la Guerra Fría (19621973). Estudios Públicos, 72, 149-171.

Gárate, M. (2012). La Revolución Capitalista de Chile (1973-2003). Santiago: Ediciones Universidad Alberto Hurtado. 
. (2015a). Las Privatizaciones como Representación

"Fetiche" del Modelo Económico Chileno (1985-2013). En Guajardo, G. y Labrador, A. (Coords.), La Empresa Pública en México y en América Latina. Entre el mercado y el Estado. México: UNAM-CEIICH / Instituto Nacional de Administración Pública, A.C.

. (2015b). El Nacimiento de un Monstruo. El Golpe de Estado en Chile y la Imagen de Augusto Pinochet a Través de las Caricaturas de la Prensa Escrita Francesa (1973-1990). Caravelle, 104, 87-114.

Gazmuri, C. (1980). Testimonios de una Crisis. Chile: 1900-1925. Santiago: Editorial Universitaria.

Guajardo, G. (2007). Tecnología, Estado y Ferrocarriles en Chile, 18501950. Madrid-México: Fundación de los Ferrocarriles Españoles, CEIICH-UNAM.

. (2018). Las Empresas Públicas Chilenas: Una Historia de Diversidad, Crisis y Continuidad, 1811-2010. En: Estefane, A. Robles, C. (Eds.) Historia politica de Chile, 1810-2010. Tomo III: Problemas económicos. Santiago: Fondo de Cultura Económica, Universidad Adolfo Ibáñez.

Guajardo, G. y Labrador, A. (Coords.) (2015). La Empresa Pública en México y en América Latina. Entre el mercado y el Estado. México: UNAM-CEIICH / Instituto Nacional de Administración Pública, A.C.

Hachette, D. (2000). Privatizaciones: Reforma Estructural, Pero Inconclusa. En Larraín, F. y Vergara, R. (Eds.), La Transformación Económica De Chile. Santiago: Centro de Estudios Públicos.

Harmer, T. y Riquelme Segovia, A. (Eds.) (2014). Chile y la Guerra Fría Global. Santiago: RIL Editores, Instituto de Historia Pontificia Universidad Católica de Chile.

Hayek, F. A. (2000). Camino de Servidumbre. Madrid: Alianza Editorial.

Humud, C. (1974): Política Económica Chilena desde 1830 a 1930. Estudios de Economía, 1 (1), 1-122. 
Huneeus, C. (2009). La Guerra Fría Chilena: Gabriel González Videla y la Ley Maldita. Santiago: Debate.

Ibáńez, A. (1983). Los Ingenieros, el Estado y la Política en Chile. Del Ministerio de Fomento a la Corporación de Fomento, 1927-1939. Historia, 18, 45-102.

Infante, J. (1961). Empresas del Estado. Tesis (Licenciatura en Ciencias Jurídicas y Sociales). Santiago, Universidad de Chile.

Kay, C. (1989). Latin American Theories of Development and Underdevelopment. Londres: Routledge.

Larroulet, C. (1987). Visión del Gobierno sobre el Estado-Empresario. Revista Chilena de Derecho, 14, 155-169.

Leffler, M. y Westad, O. (2011). The Cambridge History of the Cold War, 3 vols. Cambridge: Cambridge University Press.

Loth, W. (2011). The Cold War and the Social and Economic History of the Twentieth Century. En: Leffler, M. y Westad, O. (Eds.), The Cambridge History of the Cold War. Vol. 2. Cambridge: Cambridge University Press.

Mamalakis, M. J. (1989) Historical Statistics of Chile: Government Services and Public Sector and a Theory of Services. Westport: Greenwood Press.

Martner, G. (1988). El Gobierno del Presidente Salvador Allende 19701973. Santiago: Editorial LAR.

McPherson, A. L. (2003). Yankee No! Anti-Americanism in U.S.-Latin American Relations. Cambridge: Harvard University Press.

Medina, E. (2011). Cybernetic Revolutionaries: Technology and Politics in Allende's Chile. Cambridge: The MIT Press.

Meller, P. (1990). Una Perspectiva de Largo Plazo del Desarrollo Económico Chileno, 1880-1990. En Blomström, M. y Meller, P. (Eds.), Trayectorias Divergentes. Comparación de un Siglo de Desarrollo Económico Latinoamericano y Escandinavo. Santiago: CIEPLANHachette. 
Mönckeberg, M. O. (2015). La Máquina para Defraudar. Los casos Penta y Soquimich. Santiago: Debate.

Muñoz Gomá, O. (1986). Chile y su Industrialización. Pasado, Crisis y Opciones. Santiago: CIEPLAN.

Musso, F. (1985). Las Empresas Públicas en el Sistema Politico Chileno. Santiago: Instituto de Ciencia Política, Pontificia Universidad Católica de Chile.

Nazer, R. (Dir.). (2009). Historia de la Corporación de Fomento de la Producción, CORFO: 1939-2009. Santiago: Patrimonio Consultores.

Oficina de Planificación Nacional (ODEPLAN). (1971). Asesoría Dirección. Santiago: ODEPLAN.

Ossa, C. (1972). Estrategia de Desarrollo Industrial: Algunos Antecedentes Empíricos. En Muñoz Gomá, O. et al. (Eds.), Proceso a la Industrialización Chilena. Santiago: Ediciones Nueva Universidad.

Palma, E. (2012). Estado y Planificación. El Caso de Chile. Santiago: Gráfica Funny.

Palma, G. (1983). Chile 1914-1935: De Economía Exportadora a Sustitutiva de Importaciones. Nueva Historia. Revista de Historia de Chile, 2 (7), 165-192.

Palma, G. y Marcel, M. (1990). Kaldor y el "Discreto Encanto" de la Burguesía Chilena. Colección Estudios CIEPLAN, 28, 85-120.

Powaski, R. (2000). La Guerra Fría: Estados Unidos y la Unión Soviética, 1917-1991. Barcelona: Editorial Crítica.

Superintendencia de Compañía de Seguros, Sociedades Anónimas y Bolsas de Comercio (1970). Revista de la Superintendencia de Compañias de Seguros, Sociedades Anónimas y Bolsas de Comercio. 19, diciembre. Santiago: Superintendencia de Compañía de Seguros, Sociedades Anónimas y Bolsas de Comercio.

Rodríguez Grez, P. (1971). Manifiesto Nacionalista. Frente Nacionalista Patria y Libertad. Santiago: SOPECH. 
Rodríguez Weber, J. (2017). La Erosión del Poder de la Élite en Chile entre 1913 y 1970. Una aproximación desde los Ingresos del 1\%. Revista de Historia Económica. Journal of Iberian and Latin American Economic History, 35 (1), 49-80.

Rostow, W. W. (1973). Autoridad pública y Empresa Privada: Perspectiva Histórica por el Prof. Walt W. Rostow. En Sempere, J. A. (Comp.), Empresa Pública Versus Empresa Privada en Economias en Proceso de Desarrollo. IV Semana Económica Internacional. Barcelona: DOPESA.

Salazar, G. (1983). Historiadores, Historia, Estado y Sociedad. Comentarios críticos en torno al Ensayo Histórico sobre la Noción de Estado en Chile en los Siglos XIX y XX, de Mario Góngora. Nueva Historia. Revista de Historia de Chile, 2 (7), 193-201.

(2015). La Enervante Levedad Histórica de la Clase Politica Civil (Chile, 1900-1973). Santiago: Debate.

Silva, E. (1996). The State and Capital in Chile. Business, Elites, Technocrats, and Market Economics. Boulder: Westview Press.

Silvert, K. H. (1948). The Chilean Development Corporation. Tesis (Doctorado en Ciencia Política), Filadelfia, University of Pennsylvania, Estados Unidos.

Soares, G. (2001). Subdesarrollo Económico y Social y Homicidios en el Distrito Federal, Brasil, 1995-1998. En Rolando, F. (coord.), Sociología del Desarrollo, Politica Sociales y Democracia. Estudios en Homenaje a Aldo E. Solari. México: Siglo Veintiuno Editores, CEPAL.

Stallings, B. (2001). Las reformas estructurales y el desempeño económico. En: Ffrench-Davis, R. y Stallings, B. (Eds.), Reformas, Crecimiento y Politicas Sociales en Chile desde 1973. Santiago: LOM -CEPAL.

Taffet, J. F. (2001). Alliance for What? United States Development Assistance in Chile during the 1960s. Tesis (Doctorado en Historia). Washington DC, Georgetown University, Estados Unidos.

Urquidi, V. (1998). Incidentes de Integración en Centroamérica y Panamá, 1952-1958. Revista de la CEPAL, volumen extraordinario, 259-267.

Valdés, J. G. (1995). Pinochet's Economist: The Chicago School in Chile. Nueva York y Cambridge: Cambridge University Pres. 
Varas, A. y Fuentes, C. (1994). Defensa Nacional, Chile 1990-1994. Modernización y Desarrollo. Santiago: FLACSO.

Véliz, C. (1961). Historia de la Marina Mercante de Chile. Santiago: Ediciones de la Universidad de Chile.

Westad, O. (2011). The Cold War and the International History of the Twentieth Century. En Leffler, M. y Westad, O. (Eds.), The Cambridge History of the Cold War. Vol. 1. Cambridge: Cambridge University Press.

Winock, M. (Ed.) (1994). Le Temps de la Guerre Froide. Du Rideau de Fer à L'Effondrement du Communisme. Paris: Editions du Seuil.

\section{Leyes y decretos}

Decreto Ley 1.350. (Crea la Corporación Nacional del Cobre de Chile. 30 de enero de 1976). Biblioteca del Congreso Nacional de Chile. Consultado 25 de julio de 2016. URL: http://www.leychile.cl/Navega $\mathrm{r} /$ ?idNorma=6578\&idVersion=2010-03-01\&idParte [30-06-2018].

Ley 18971 (Ministerio de Economía, Fomento y Reconstrucción. Establece recurso especial que indica) Fecha Publicación 10-03-1990. Legislación Chilena. Biblioteca del Congreso Nacional de Chile. URL: http:// www.leychile.cl/N?i=30339\&f=1990-03-10\&p= [30-06-2018].

Ley 12927. Seguridad Interior del Estado. Biblioteca del Congreso Nacional de Chile. URL: http://www.leychile.cl/Navegar?idNorma= 27292\&idVersion=1958-08-06 [30-06-2018].

Recibido: 10-05-2017

Aceptación de la versión final: 31-05-2017 